\title{
An Animal Model of Early-treated PKU
}

\author{
Adele Diamond,, ${ }^{1,2}$ Vivian Ciaramitaro,, ${ }^{2}$ Elizabeth Donner, ${ }^{2}$ Sina Djali, ${ }^{3}$ and Michael B. Robinson ${ }^{2,3}$ \\ 'Department of Psychology, ${ }^{2}$ Mahoney Institute of Neurological Sciences, and ${ }^{3}$ Departments of Pediatrics and \\ Pharmacology and Children's Seashore House, University of Pennsylvania School of Medicine, University of Pennsylvania, \\ Philadelphia, Pennsylvania 19104
}

Phenylketonuria (PKU) is a genetic disorder in which the hydroxylation of phenylalanine (Phe) to tyrosine is severely disrupted. If PKU is left untreated, severe mental retardation results. The accepted treatment is to restrict dietary intake of Phe. It has generally been thought that cognitive impairments are prevented if levels of Phe in plasma are maintained at or below five times the normal level. However, we recently documented that children treated early and continuously for PKU or children mildly hyperphenylalaninemic, who have levels of Phe in plasma approximately three to five times normal, still have cognitive impairments. These impairments are specific to the functions of frontal cortex (A. Diamond, W. Hurwitz, E. Lee, W. Grover, and C. Minarcik, unpublished observations). To investigate the mechanism underlying these cognitive deficits, an animal model of this condition was developed and characterized.

Thirty-six rat pups were divided into three groups. The first group was treated pre- and postnatally with Phe and $\alpha$-methylphenylalanine (a phenylalanine hydroxylase inhibitor). The second group was injected postnatally with Phe and $\alpha$-methylphenylalanine. The third group received postnatal control injections. The mild plasma Phe elevations in the two experimental groups produced significant behavioral and neurochemical effects. Both experimental groups were impaired on a task dependent on frontal cortex, delayed alternation. Levels of dopamine, homovanillic acid (HVA), norepinephrine, and 5-hydroxyindole acetic acid (5-HIAA) were measured in medial prefrontal cortex, anterior cingulate cortex, striatum, and nucleus accumbens. The largest neurochemical reductions observed were in HVA and were in the two frontal cortical areas (medial prefrontal cortex and anterior cingulate cortex). There were modest reductions in HVA in the nucleus accumbens but no significant changes in HVA, or in any other metabolite or neurotransmitter, in the

\footnotetext{
Received June 21, 1993; revised Sept. 17, 1993; accepted Nov. 1, 1993.

This work was supported by BRSG S07 RR07083-26 and by MRRC P30-HD26979. M.B.R. is an Alfred P. Sloan Fellow. Wc thank the veterinarian, Mark Jamba, for his attentiveness to the health of our animals, Mark Stanton for much help on the details of behavioral testing and for the loan of his maze, Olga Greengard for information on administering $\alpha$-methylphenylalanine + Phe to raise $P$ Pe levels chronically, Bethany Neal and Jay Schneider for their assistance with the brain dissections, Ariel Deutch for detailed information on procedures to minimize stress prior to dissection and on the anatomical boundaries for the dissections Eliot Stellar for the use of the larger T-maze for juvenile testing, Phil Arnell for instructions on the operation of that maze, Bill $\mathrm{Li}$ and Tim Bockes for statistical analyses, Victor Auerbach for his advice during the nascent stages of this project, and Barbara Strupp for her comments on an earlier draft of our paper.

Correspondence should be addressed to Adele Diamond, University of Pennsylvania, Department of Psychology, 3815 Walnut Street, Philadelphia, PA 191046196.

Copyright (C) 1994 Society for Neuroscience $0270-6474 / 94 / 143072-11 \$ 05.00 / 0$
}

striatum. The levels of 5-HIAA were also reduced in all brain regions examined. There was no effect on norepinephrine in any of the four regions examined. Reduced levels of HVA in medial prefrontal cortex were the only neurochemical effect that significantly correlated with every measure of performance on the delayed alternation task.

This study provides evidence of deleterious effects from mild elevations in the levels of Phe in plasma previously considered small enough to be safe. These effects include impaired performance on a cognitive task dependent on frontal cortex and reduced HVA levels in frontal cortex. It is not possible to rule out a role for other neurotransmitter systems from this study alone, but the results of other investigations suggest that the behavioral impairment is due to the alterations in the dopamine system in frontal cortex.

IKey words: phenylketonuria, phenylalanine, tyrosine, prefrontal cortex, anterior cingulate, dopamine, homovanillic acid, 5-HT, inherited metabolic disorder, delayed alternation, memory]

Phenylketonuria (PKU) is most commonly caused by mutations of the gene in chromosome 12 that codes for phenylalanine hydroxylase (Woo et al., 1983; Lidsky et al., 1985; DiLella et al., 1986). Phenylalanine hydroxylase is essential for the conversion of phenylalanine (Phe) to tyrosine. Other mutations in this gene are the most common cause of milder forms of hyperphenylalaninemia (Ledley et al., 1986; Levy et al., 1971). These deficits in Phe metabolism result in increases in the level of Phe in the bloodstream (e.g., Krause et al., 1985) and often cause decreases in the level of tyrosine in blood. If untreated, PKU results in widespread brain damage and severe mental retardation (e.g., Hsia, 1970; Cowie, 1971). The treatment for PKU is a diet low in Phe. When begun early and consistently maintained, this diet averts the most severe consequences of PKU. Neither gross structural brain damage nor global cognitive impairments are found (e.g., Bickel et al., 1954; Hudson et al., 1970; Williamson et al., 1981). Unfortunately, recent data indicate that there are deficits in the cognitive abilities dependent on frontal cortex even in children who have been on a restricted diet since birth, if those children have three- to fivefold elevations in plasma Phe (e.g., Welsh et al., 1990; A. Diamond, W. Hurwitz, E. Lee, W. Grover, and C. Minarchik, unpublished observations). These elevations were previously thought to be benign. The cognitive deficits appear to be specific; the children's performance on tasks dependent on parietal cortex or the medial temporal lobe is normal (Diamond, Hurwitz, Lee, Grover, and Minarchik, unpublished observations).

While the Phe-restricted diet succeeds in greatly lowering Phe concentrations in plasma from their untreated levels $(>20 \mathrm{mg} /$ 


\begin{tabular}{|c|c|c|}
\hline $\begin{array}{l}\text { Experimental } \\
\text { conditions }\end{array}$ & $\begin{array}{l}\text { Prenatal } \\
\text { treatment }\end{array}$ & $\begin{array}{l}\text { Postnatal } \\
\text { treatment }\end{array}$ \\
\hline $\begin{array}{l}\text { Mildly elevated Phe levels } \\
\text { pre- and postnatally } \\
(N=12 ; 6 \mathrm{M}, 6 \mathrm{~F})\end{array}$ & $\begin{array}{l}\text { Mothers fed liquid diet supple- } \\
\text { mented with } 0.5 \% \alpha \text {-methyl- } \\
\text { phenylalanine }{ }^{a}+2 \% \text { Phe be- } \\
\text { ginning on gestational day } 3 \text {. }\end{array}$ & $\begin{array}{l}\text { Daily injections of } \alpha \text {-methylphe- } \\
\text { nylalanine }(24 \mu \mathrm{mol} / 10 \mathrm{gm} \\
\text { body wt })+ \text { Phe }(12 \mu \mathrm{mol} / 10 \\
\text { gm body wt }) \text { beginning on } \mathrm{P} 4 \text {. }\end{array}$ \\
\hline $\begin{array}{l}\text { Mildly elevated Phe levels post- } \\
\text { natally } \\
(N=12 ; 6 \mathrm{M}, 6 \mathrm{~F})\end{array}$ & Mothers fed normal liquid diet. & $\begin{array}{l}\text { Daily injections of } \alpha \text {-methylphe- } \\
\text { nylalanine }(24 \mu \mathrm{mol} / 10 \mathrm{gm} \\
\text { body } \mathrm{wt})+ \text { Phe }(12 \mu \mathrm{mol} / 10 \\
\text { gm body wt) beginning on P4. }\end{array}$ \\
\hline $\begin{array}{l}\text { Controls } \\
(N=12 ; 6 \mathrm{M}, 6 \mathbf{F})^{b}\end{array}$ & Mothers fed normal liquid diet. & $\begin{array}{l}\text { Daily control injections of saline } \\
\text { beginning on P4. }\end{array}$ \\
\hline
\end{tabular}

a $\alpha$-Methylphenylalanine is an inhibitor of the enzyme phenylalanine hydroxylase.

${ }^{\prime}$ Every subject assigned to the control group was matched to a littermate of the same sex and size in the second experimental group. One male rat in the control group died of unknown causes in early infancy.

$\mathrm{dl} ;>1200 \mu \mathrm{mol} /$ liter), it rarely succeeds in bringing them down to normal $(2 \mathrm{mg} / \mathrm{dl})$. For this reason, even children treated early for PKU and maintained on diet have moderately elevated plasma levels of Phe (4-10 mg/dl). Children with mild hyperphenylalaninemia have comparable elevations in plasma Phe while on a normal diet. Because these levels had been thought acceptable, mildly hyperphenylalaninemic children are not usually placed on a restricted diet.

Since Phe and tyrosine compete for the same transporter proteins to cross the blood-brain barrier, increases in the ratio of Phe to tyrosine in plasma result in less tyrosine crossing into the brain (Chirigos ct al., 1960; Pardridgc and Olcndorf, 1977; Miller et al., 1985), especially since the transporters have a higher affinity for Phe than for tyrosine (Pardridge and Olendorf, 1977; Miller et al., 1985). Most areas of the brain receiving dopaminergic input are insensitive to small changes in the level of tyrosine; prefrontal cortex is an exception. The dopaminergic neurons innervating prefrontal cortex appear to have higher levels of activity and higher dopamine turnover than most other dopaminergic neurons, and may also lack the synthesis-modulating autoreceptors present on most other dopaminergic neurons (Bannon et al., 1981a,b, 1982; Chiodo et al., 1984; Roth, 1984). This makes prefrontal cortex acutely sensitive to even a small change in tyrosine levels (Thierry et al., 1977; Chiodo et al., 1984; Tam et al., 1991). Indeed, reductions in tyrosine that have little or no effect on dopamine systems in much of the brain, profoundly reduce the amount of dopamine metabolized in prefrontal cortex (c.g., Bradberry et al., 1989). In addition, dopamine synthesis can also be affected by the competitive inhibition exerted by high levels of Phe on tyrosine hydroxylase activity (Levitt et al., 1965; Ikeda et al., 1967; McKean, 1972).

Furthermore, the cognitive functions subserved by frontal cortex are acutely sensitive to reductions in dopamine in frontal cortex. Selectively depleting prefrontal cortex of dopamine produces cognitive impairments as severe as those found after removal of frontal cortex (Brozoski et al., 1979). Indeed, local injection of dopamine antagonists into frontal cortex impairs performance on tasks dependent on prefrontal cortex in a precise, dose-dependent manner (Sawaguchi and Goldman-Rakic, 1991).

Given that (1) children with early-treated PKU or mild hyperphenylalaninemia have moderately elevated plasma levels of Phe, (2) moderate elevations in plasma Phe are capable of reducing brain levels of tyrosine only mildly, (3) the levels of dopamine in frontal cortex are affected by mild reductions in tyrosine too small to affect dopamine levels in most other brain regions, and (4) reductions in frontal cortex dopamine levels produce cognitive deficits similar to those observed in children with early-treated PKU or mild hyperphenylalaninemia, we hypothesized that the cognitive deficits in these children might be caused by reductions in dopamine metabolism in frontal cortex. To test this hypothesis, we developed what we believe to be the first animal model of early-treated PKU. The cognitive performance of these treated animals was compared to littermate controls using a task dependent on frontal cortcx and the levels of biogenic amine neurotransmitters and their metabolites in the treated animals were measured.

\section{Materials and Methods}

Pharmacological treatment. Thirty-six Long Evans Hooded rats were bred from multiparous dams obtained from Charles River Breeders (Wilmington, MA). These rats were divided into three groups (see Table $1)$.

For some children with PKU, imbalances in the levels of Phe and tyrosine begin in utero (Lenke and Levy, 1980; Bessman et al., 1988). This can happen, for example, if the mother's plasma Phe levels are moderately elevated. To examine effects that begin prenatally and continue postnatally, animals in cxperimental group 1 were exposed to moderately elevated Phe levels beginning in utero. Beginning on day 3 after mating, their mothers were fed a diet supplemented with $0.5 \%$ $\alpha$-methylphenylalanine (a partial inhibitor of phenylalanine hydroxylase; Greengard et al., 1976) plus 2\% Phe (chemicals supplied by Sigma Chemical, St. Louis, MO). To keep Phe levels elevated for as much of the day as possible, the pregnant dams were fed in small amounts six times daily. Prior work has already demonstrated that elevated maternal levels of Phe are transmitted to the fetus via the placenta (e.g., Kerr et al., 1968; Wapnir and Dierks-Vertling, 1971; Levy and Waisbren, 1983) and that dietary supplementation such as used here raises Phe levels in the plasma and brain of both mother and fetus (Brass and Greengard, 1982; Brass et al., 1982). These investigators employed the same percentage of $\alpha$-methylphenylalanine as used in the present study, but more Phe (3-5\%; Brass and Grecngard, 1982; Brass et al., 1982). The reason higher doses of Phe were used in these prior studies is that the investigators were trying to model untreated PKU.

Another nine dams received the same diet without the addition of $\alpha$-methylphenylalanine or Phe. Because the liquid diet lacked fiber and the added Phe reduced its palatability, both the normal and Phe-enriched diets were supplemented with $5 \%$ fiber and chocolate (diets prepared by Bioserve Co., Frenchtown, NJ). To ensure that pregnant dams in the control and experimental groups consumed equal amounts of food, each dam on the normal diet was yoked to a dam on the Pheenriched diet. Those on the Phe-enriched diet were provided with food 
ad lib. Each dam on normal diet was fed the amount her match had eaten on the preceding day. Upon parturition, all dams were placed on a normal solid diet of Purina rat chow.

Pups of dams on the Phe-enriched diet were injected daily with $\alpha$-methylphenylalanine and Phe, beginning on postnatal day 4 (P4) and continuing through the day of death (see Table 1). This is experimental group 1; they were exposed to elevations of Phe in utero and after birth. Pups of dams on normal diet were divided into two groups: one group received the same daily injections (experimental group 2: elevations in Phe only postnatally); the final group rcceived daily injections of saline (the controls).

Both experimental groups received the same postnatal treatment; they differed only in the diet their mothers had been fed during pregnancy. Experimental group 2 and the controls were littermates, matched for sex, weight, and size; they differed only in their postnatal treatment. The daily subcutaneous injections were prepared according to the protocol of DelValle and Greengard (DelValle et al., 1978; Brass and Greengard, 1982) and began on postnatal day 4 (P4). P4 is when dopamine innervation of rat prefrontal cortex appears to begin (Kalsbeek et al., 1988 ) and is roughly the same age when previous investigators began their treatments to cause elevations in Phe (Greengard et al., 1976; DelValle et al., 1978; Brass and Greengard, 1982). Each experimental animal received two consecutive injections, one of $\alpha$-methylphenylalaninc and onc of Phe. Previous work had demonstrated that treatment results in Phe levels that remain elevated for at least 16-18 hr postinjection (DelValle et al., 1978), and that daily injections continue to be effective even after several weeks (Greengard et al., 1976; DelValle et al., 1978). Each control animal received two consecutive injections of saline isovolumetric with the $\alpha$-methylphenylalanine and Phe injections for that animal's body weight. As was indicated above for the dietary treatment of pregnant dams, previous investigators injected the same percentage of $\alpha$-methylphenylalanine as employed in the present study, but four times as much Phe (Greengard et al., 1976; DelValle et al., 1978; Brass and Greengard, 1982). In these prior studies, the dosage of Phe was higher because these studies were designed to model the higher Phe concentrations found in untreated PKU.

To determine the effectiveness of the Phe manipulation, plasma Phe lcvels were mcasurcd in blood samples drawn from the tail vein $2 \mathrm{hr}$ postinjection at three different ages [the day before infant behavioral testing (P19), the day following the conclusion of infant testing (P27), and the day following juvenile testing (P47)]. Plasma Phe analyses were performed by Roche Biomedical Labs (Raritan, NJ) using the Guthrie modified bacterial inhibition assay procedure (Guthrie and Susi, 1963).

Behavioral testing. All animals were tested on delayed alternation, a task sensitive to frontal cortex damage in both rats (e.g., Wikmark et al., 1973; Larsen and Divac, 1978; Bubser and Schmidt, 1990) and primates (e.g., Jacobsen and Nissen, 1937; Bättig et al., 1960; Kubota and Niki, 1971). On trial 1 of each delayed alternation session, the reward was delivered at whichever goal arm of the T-maze the animal entered. Thereafter, the animal was rewarded only for entering the goal arm not chosen on the preceding trial. The name of the task derives from the fact that animals must learn to alternate goal arms, and must remember which goal arm was last entered over the delay imposed between trials. No visual or olfactory cues within the maze signaled the correct choice since (1) the goal arms were identical, (2) the reward was delivered only after an animal had selected a goal arm, and (3) the maze was thoroughly cleaned between animals to remove scent markings. Testing began immediately after weaning and continued for 1 week (infant testing: P20-P26; delays of 0, 10,30, and $90 \mathrm{sec}$ ), with retesting 1 month later (juvenile testing: P45-P46; delays of 0 and $90 \mathrm{sec}$ ).

Rat pups were removed from their mothers on the evening of P18, although they continued to be group housed with same-sex littermates. As infants, male rats were run in the same infant $T$-maze used by Green and Stanton (1989), and females were run in a replica of that maze. Both mazes were made of opaque Plexiglas and consisted of a start box $(23 \times 8 \mathrm{~cm})$ that opened to a straight central runway $(8 \times 8 \mathrm{~cm})$ leading to left and right goal arms (each $23 \times 8 \mathrm{~cm}$ ). Opaque doors separated the start box from the choice area and the choice area from each of the goal arms. The mazes were placed on a long table with one of the two $7.5 \mathrm{~W}$ bulbs illuminating the room above each maze.

Familiarization to these mazes occurred on postnatal day 19 and consisted of two goal box training sessions and one forced choice training session [same procedure used by Freeman and Stanton (1991)]. In the first goal box training session, each subject received six 3 min exposures to the same goal arm, receiving $0.05 \mathrm{ml}$ of cream each time, with $9 \mathrm{~min}$ between each exposure. The second session was the same except that each animal was placed in the other goal arm of the same maze. For forced choice training, an animal was placed in the start box, and the door of only one goal arm was raised. The pup was rewarded for entering the goal arm. This was repeated for a total of 12 trials, six to the right and six to the left, in random order.

Each testing session consisted of a block of 12 trials at a given delay. The criterion for passing the task at a given delay was 10 out of 12 trials correct. Delay was only incremented if the subject passed criterion at the current delay. At the end of each trial, the subject was confined to the goal arm for $20 \mathrm{sec}$ (for consumption of the $0.075 \mathrm{ml}$ cream reward if correct, or as punishment if incorrect). Animals were placed in individual holding cages for at least $1 \mathrm{hr}$ prior to testing (to allow the stress of removal from group housing to subside), and for $2 \mathrm{hr}$ following testing, during which time they were weighed and fed. A given animal was tested by one experimenter and injected by another; the three testers were blind to the group assignments of their animals (two males and two females per tester in each of the three conditions).

Previous work has demonstrated that the levels of Phe in plasma are maximally elevated during the few hours after injection (DelValle et al., 1978; Brass and Greengard, 1982). To determine whether there was an acute effect of higher levels of Phe superimposed on the effect of chronic Phe elevation.Performance on the delayed alternation task $3.5 \mathrm{hr}$ after injection (postinjection) was compared to performance $20 \mathrm{hr}$ after injection [equivalent to $4 \mathrm{hr}$ prior to injection (preinjection)]. For a given delay, the first testing session was always administered preinjection.

Juvenile rats were tested in the adult-size $\mathrm{T}$-maze, consisting of a start box $(20 \times 15 \mathrm{~cm})$, central runway $(22.5 \times 15 \mathrm{~cm})$, and left and right goal arms (each $51.25 \times 15 \mathrm{~cm}$ ), described by Zhang et al. (1984). Familiarization training occurred on P44 and consisted of one 2 min goal box training trial per goal arm and six forced-choice trials in the order L-R-L-R-L-R. Because of the shortness of the retest period, animals were tested only postinjection. The criterion for passing a given delay was still 10 out of 12 trials correct within a block. Only animals that succeeded at the shorter delay were tested at the longer delay. The reward was liquid rat diet supplemented with fiber and chocolate, a treat that the rats had not had since the days of infant testing.

Biochemical analyses of the brains. Two cortical and two subcortical areas were dissected bilaterally. The two cortical arcas wcre mcdial prefrontal cortex and anterior cingulate cortex, the two cortical areas highest in dopamine in the rat (Thierry et al., 1973; Berger et al., 1974, 1976; Lindvall and Bjorklund el al., 1978; Berger et al., 1985). Medial prefrontal cortex in the rat is generally considered the homolog of the dorsolateral prefrontal cortex in the primate (Leonard, 1969; Domesick, 1972; Kolb, 1984; Groenewegen, 1988). The two subcortical areas dissected, the caudate-putamen (striatum) and the nucleus accumbens, are the two subcortical areas that have the highest levels of dopamine (Fuxe, 1965).

The four brain regions were anatomically defined as follows. Medial prefrontal cortex corresponds to Brodmann's area 32 (e.g., Brodmann, 1909). It is located immediately in front of the genu and extends down midway through the brain in coronal section. Anterior cingulate cortex (area 24 or 24B of Vogt and Peters, 1981) is also part of frontal cortcx and is located immediately behind medial prefrontal cortex and above the genu (Berger et al., 1976; Lindvall and Bjorklund, 1978; Lindvall et al., 1978). The caudate-putamen, or striatum, is the large area immediately below the corpus callosum and is especially easy to discern in the rat. For dissection of the nucleus accumbens, we used the anterior commissure (above) and the olfactory tubercle (below) as landmarks. An excellent diagram illustrating the location of all of these areas is provided in Deutch et al. (1985).

Given the sensitivity of dopamine in frontal cortex to stress (e.g., Thierry et al., 1976; Reinhard et al., 1982; Roth, 1984), precautions were taken to keep the animals as calm and undisturbed as possible prior to dissection (similar to precautions used by A. Y. Deutch, personal communication). All animals were killed by decapitation $2 \mathrm{hr}$ postinjection (range, 1.97-2.25 hr) on P62 and the four brain regions disscetcd in coronal section over ice. The tissue was frozen in dry ice immediately after dissection and stored at $-70^{\circ} \mathrm{C}$. The order of death was one female from each of the three experimental groups, and then one male from each of the three groups, with order within each group of three randomized across experimental conditions.

The levels of dopamine, homovanillic acid (HVA; a dopamine metabolite), norepinephrine, and 5-hydroxyindole acetic acid (5-HIAA; a metabolite of 5-HT) were measured using reverse-phase HPLC analysis with an electrochemical detector as described in Robinson et al. (1992). At the time of analysis, the samples were reweighed and diluted 10 -fold 
in $0.1 \mathrm{M}$ cold acetate buffer, containing $100 \mathrm{~nm}$ dihydroxybenzylamine as an internal standard. The tissue was then sonicated for $10 \mathrm{sec}$ and centrifuged at $29,000 \times g$ for $10 \mathrm{~min}$. The bilateral dissections for each brain region from a given animal were analyzed independently and then averaged. First, all the tissues from two animals in each group were analyzed. The remaining analyses were performed by assaying one region at a time from all animals. The person performing these analyses was kept blind as to the group assignments of the animals.

A model 510 pump in conjugation with a WISP model 712 (Waters Co., MA), and a pulse damper (ESA, MA) served as the solvent delivery system. The chromatographic column was a Brownlee $10 \mathrm{~cm}, 4.6$ i.d. C 18 reverse-phase column, preceded by Brownlee Guard OD-GU $3 \mathrm{~cm}$, $4.6 \mathrm{~mm}$ i.d. (Rainin, CA). An electrochemical detector model $5100 \mathrm{~A}$ Coulochem with a model 5011 analytical cell was used for the analysis of the biogenic amines and catecholamines. The detector setting was the following: detector $1,+0.03 \mathrm{~V}$; detector $2,+0.55 \mathrm{~V}$. The mobile phase consisted of sodium acetate at $50 \mathrm{~mm}$ (Baker Inc., NJ), disodium FDTA at $50 \mu \mathrm{M}$ (Sigma), sodium 1-octanesulfonate at $6 \mathrm{~mm}$ (Kodak, $\mathrm{NY}$ ), $5 \mathrm{vol} \%$ acetonitrile (Baker), and $950 \mathrm{ml}$ of double distilled deionized water (in-house unit). The $\mathrm{pH}$ was adjusted to 3.3 with $85 \%$ phosphoric acid. The mobile phase was filtered using a $0.22 \mu \mathrm{m}$ filter (Millipore, MA) and degassed under vacuum. All the chemicals were of analytic grade. Under these conditions, serotonin elutes as a broad peak late in the chromatogram and, therefore, was not analyzed. 3,4-Dihydroxyphenylacetic acid (DOPAC), another metabolite of dopamine, was not analyzed because it too elutes close to the front under the chromatographic conditions used here.

\section{Results}

Phenylalanine manipulation. The mean Phe level for control rats was $2.2 \mathrm{mg} / \mathrm{dl}$. Our manipulation raised the mean Phe level 6.4 times control levels in the first experimental group and 6.0 times control levels in the postnatally treated group (see Table 2 ; mean for the two groups $=13.7 \mathrm{mg} / \mathrm{dl}$ ).

Phe levels at P19 and P27 were within, or close to, our goal of raising Phe $<5$ times normal, although at $\mathrm{P} 47$ Phe levels were higher. At P19, measured $2.25 \mathrm{hr}$ after injection, the mean Phe level of rats pre- and postnatally treated (group 1) was $13.3+$ $5.8 \mathrm{mg} / \mathrm{dl}$, the mean level in rats postnatally treated (group 2) was $15.6 \pm 4.7 \mathrm{mg} / \mathrm{dl}$, and the mean for controls was $2.7 \pm 2.4$ $\mathrm{mg} / \mathrm{dl}$. At P27, $1.8 \mathrm{hr}$ postinjection, the mean Phe levels for the experimental groups were $8.8 \pm 4.8 \mathrm{mg} / \mathrm{dl}$ and $9.2 \pm 4.7 \mathrm{mg} /$ $\mathrm{dl}$, respectively; control levels were $2.0 \pm 0 \mathrm{mg} / \mathrm{dl}$. At $\mathrm{P} 47$, measured $2 \mathrm{hr}$ postinjection, the mean Phe level was $17.6 \mathrm{mg} /$ $\mathrm{dl}\left(\mathrm{SD}_{\mathrm{G} 1}=5.7, \mathrm{SD}_{\mathrm{G} 2}=4.7\right)$ for both experimental groups and $2.0(\mathrm{SD}=0)$ for the controls. While plasma Phe levels were raised slightly more than intended, these Phe levels are much lower than those found in untreated PKU (e.g., 36-43 mg/dl, Berry et al., 1979; 21-48 mg/dl, Cabalska et al., 1977) and much less than the increase in Phe levels produced in animal models of untreated PKU (e.g., 12-18 times normal, DelValle et al., 1978; 10-33 times normal, Greengard et al., 1976). No significant difference was found between the Phe levels of the two experimental groups at any age, nor was there an overall sex difference, although among the rats treated only postnatally females showed a larger elevation in plasma Phe than did males at both P27 and P47 (females vs males: P27, $t=3.7, p<0.005$; $\mathrm{P} 47, t=2.17, p=0.05)$. Brass and Greengard (1982) also report a greater effect in female rats.

The prenatal manipulation also had an effect on mortality and body weight, although the postnatal manipulation did not. Two of the seven litters from dams on the $\alpha$-methylphenylalanine + Phe diet died of unknown causes within $24 \mathrm{hr}$ after birth. Shortly after birth (P4), the pups chosen from the remaining $\alpha$-methylphenylalanine + Phe litters (group 1) weighed roughly $20 \%$ less than pups chosen from the other litters [mean weights $=8.3 \pm 0.8 \mathrm{gm}$ (group 1), $10.0 \pm 1.3 \mathrm{gm}$ (group 2),
$10.2 \pm 1.6 \mathrm{gm}$ (controls); $F(1,32)=17.05, p<0.0003$, regression analysis of $\mathrm{P} 4$ weights in group 1 vs the other two groups]. This difference in infant mortality and weight is similar to that reported by others (e.g., Kerr et al., 1968; Brass et al., 1982; McDonald et al., 1990), and occurred despite the yoking of food intake. By P12 the difference in weight among the groups of rat pups had disappeared. From then on, the weight gains of all groups of rats were comparable (e.g., mean weight at P19: 37 $\mathrm{gm}, 37 \mathrm{gm}$, and $38 \mathrm{gm}$, respectively; at $\mathrm{P} 44: 156 \mathrm{gm}, 155 \mathrm{gm}$, and $160 \mathrm{gm}$, respectively; and at P62: $236 \mathrm{gm}, 241 \mathrm{gm}$, and 242 $\mathrm{gm}$, respectively). During the period between infant and juvenile behavioral testing, the weights of the male rats in all conditions began to exceed that of the female rats and continued to do so throughout the duration of the experiment.

Delayed alternation performance. When tested as infants (P20$\mathrm{P} 26$ ), there was no significant difference among the groups at the $0 \mathrm{sec}$ or $10 \mathrm{sec}$ delays in percent correct or in mean number of trials needed to pass criterion (see Table 2). All animals passed the $0 \mathrm{sec}$ delay and all but one passed the $10 \mathrm{sec}$ delay. At the $30 \mathrm{sec}$ delay, however, both experimental groups performed significantly worse than controls (see Table 2). At the $90 \mathrm{sec}$ delay, animals treated both pre- and postnatally (group 1) were severely impaired, but the impairment in the animals treated only postnatally (group 2) was not sufficient to achieve statistical significance.

On retesting as juveniles, the performance of group $1 \mathrm{did}$ not differ from that of controls at the 0 sec delay, but group 2 performed significantly worse (Table 2). The performance of group 2 at the $0 \mathrm{sec}$ delay may indicate that several of those animals failed to transfer what they had learned in the infant maze to the new adult maze. At the $90 \mathrm{sec}$ delay, the two experimental groups combined performed significantly worse than controls.

There was no effect of tester or of sex of the animal, and no significant interaction of either of these with any other variable. There were also no noticeable differences in activity or emotionality among animals in the different groups. Indeed, response latency was measured on every trial during both infant and juvenile testing, and there were no group differences in this whatsoever.

All animals in the experimental groups had chronically elevated plasma Phe levels. The elevations are highest soon after injection and lowest before the next day's injection (DelValle et al., 1978; Brass and Greengard, 1982). Animals were tested shortly after injection ( $3.5 \mathrm{hr}$ after) and shortly before the next day's injection ( $4 \mathrm{hr}$ before) to determine if performance is worse when Phe levels are higher. We calculated the difference in performance between all adjacent sessions within a given delay (percentage correct in later session minus percentage correct in earlier session). We compared the difference obtained when the earlier session was preinjection to the difference when the earlier session was postinjection. If animals are learning, one would expect performance to be better on later sessions. Indeed, all adjacent scssion comparisons (whether pre- to postinjection or post- to preinjection) showed improved performance in later sessions. If there is an effect of acute elevation in Phe, one would expect less improvement in later sessions that occur postinjection, when Phe levels are higher, than in later sessions that occur preinjection, when Phe levels are lower. Indeed, performance improved more when the later session occurred at a time when Phe levels are lower than when the later session occurred shortly after injection (across all delays for the two experimental groups: 


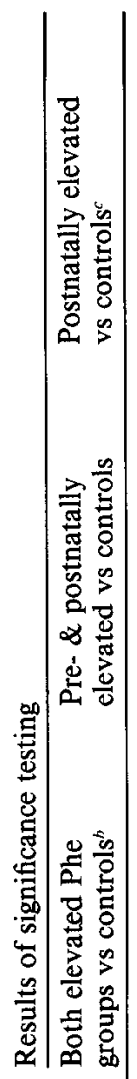

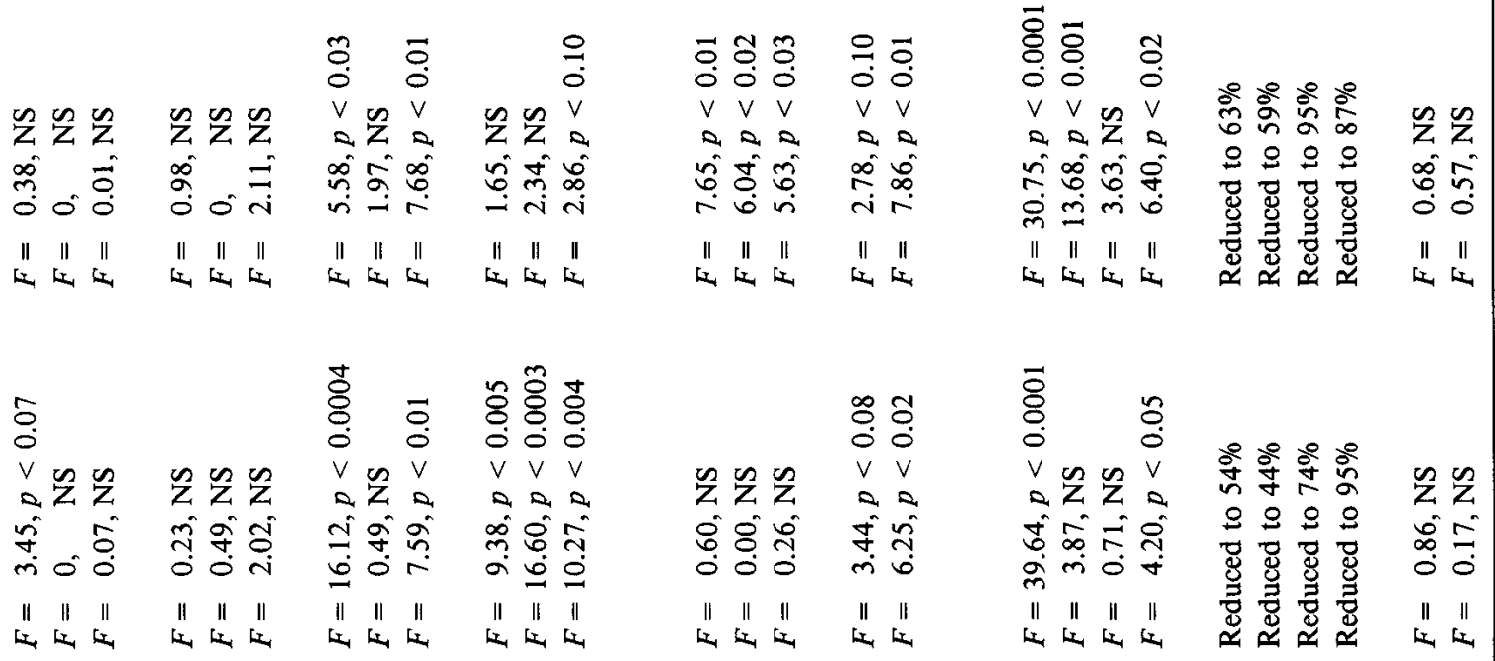

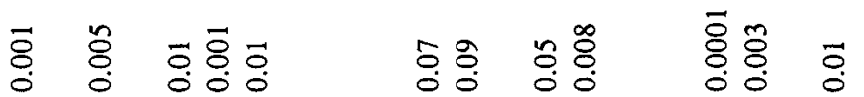

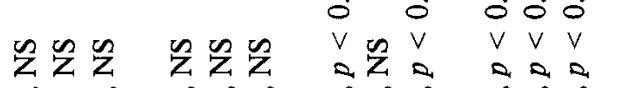

$\begin{array}{llll}n & V & V & V \\ 2 & a & 2 & a\end{array}$

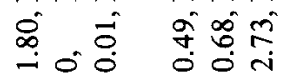

तंळ

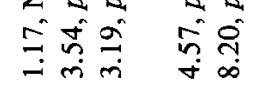

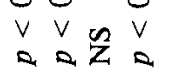

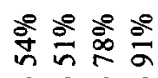

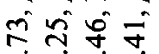

잉

웅ㅇㅇㅇ

实实

II II II

胥丰

行

守余

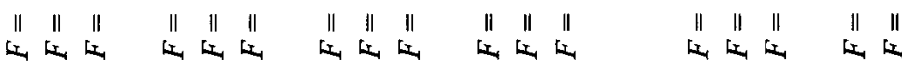

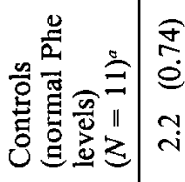

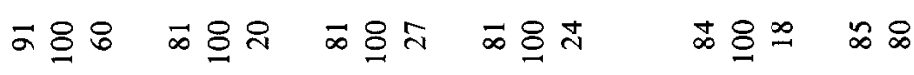

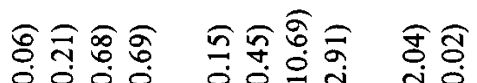

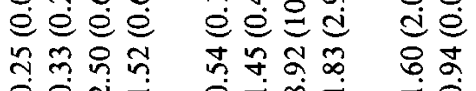

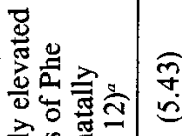

(1)

$$
\text { (2) }
$$

ఏิ

$8:$ m<smiles>C=CC(=O)O</smiles>

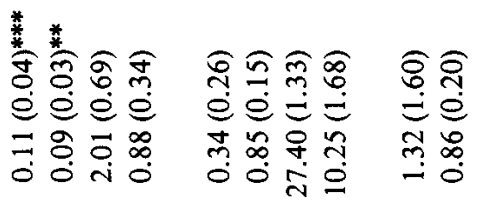
犊

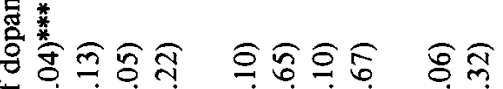
पढ仓巳巳

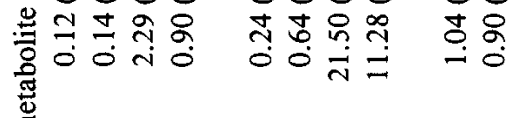

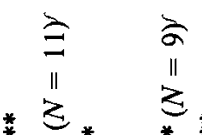

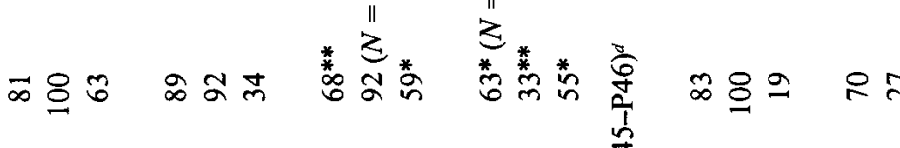

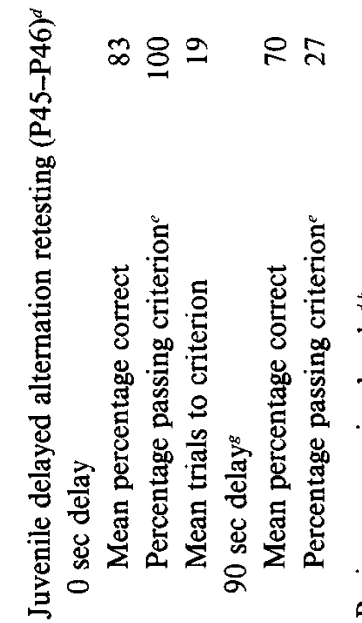

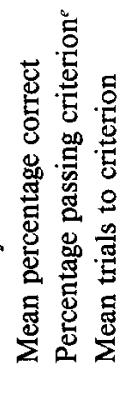

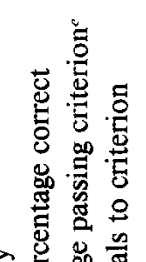

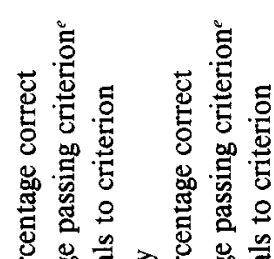

है 
within-subject $t=4.59, p<0.0001)$. This difference was greater for group 2 than for group 1 (across all delays, group 1: withinsubject $t=1.59, p=0.07$; group 2: within-subject $t=7.66, p$ $<0.0001$ ). As expected, the time interval between saline injections and testing yielded no significant effects for the control group (within-subject $t=1.1, \mathrm{NS}$ ). Within individual delays the difference in performance for both experimental groups was significant only at the $0 \mathrm{sec}$ delay (both groups together: $t=$ 4.69, $p=0.0003$; group 1: $t=2.27, p=0.041$; group $2: t=$ $4.95, p=0.002$ ). Given the marginal effect across delays for the pups in group 1 and given that at only one individual delay was the effect large enough to achieve significance, we conclude that effects of acute elevation, while present, were not prominent.

Neurotransmitter and metabolite levels. First, and most important, small elevations in plasma lcvels of Phe, previously thought to be benign, produced significant neurochemical changes. The strongest effect was on HVA in the frontal cortex. In both frontal cortical areas (medial prefrontal cortex and anterior cingulate), the levels of HVA in each experimental group were reduced to less than half $(27-48 \%)$ of those observed in control animals (see Table 2). In medial prefrontal cortex, there was almost no overlap between HVA levels of controls and of either experimental group: all control animals but one had higher HVA levels than any animal in either experimental group. The levels of HVA in the nucleus accumbens were reduced to approximately $60 \%$ of control levels. HVA was unaffected in the striatum. The levels of 5-HIAA were reduced to approximately $70 \%$ of control levels in medial prefrontal cortex and the striatum. 5-HIAA was reduced to approximately $50 \%$ of control levels in anterior cingulate cortex and nucleus accumbens. The levels of norepinephrine were not significantly affected in any of the brain regions examined.

HVA levels in medial prefrontal cortex were the only brain monoamine levels significantly related to all measures of performance on the delayed alternation task (see Table 3). The greater the reduction in HVA levels in prefrontal cortex, the worse the animal's performance on delayed alternation. HVA levels in the other three brain regions investigated were not significantly related to performance (except for one performance measure and HVA in the cingulate). No neurotransmitter or metabolite level studied in the anterior cingulate, striatum, or nucleus accumbens was significantly related to performance (with the single exception just noted). 5-HIAA levels in prefrontal cortex were significantly related to measures of performance during juvenile testing but not infant testing.

\section{Discussion}

In the present study, rats were treated with an inhibitor of phenylalanine hydroxylase plus Phe. This treatment caused an elevation in plasma Phe levels roughly comparable to those observed in children with mild hyperphenylalaninemia or with early and continuously treated PKU. While accepted opinion has maintained that these mild elevations in Phe are benign, our results document significant neurochemical and behavioral effects. These results were found in both experimental treatments, the group treated pre- and postnatally and the group treated only postnatally. Although group 1 came from different litters than the controls (and so differed genetically from the controls), the study's conclusions are the same if one compares only experimental group 2 to their same-sex littermates in the control group. Because the Phe manipulation was effective for 
Table 3. Relation between delayed alternation performance and brain metabolite levels

\begin{tabular}{|c|c|c|c|c|}
\hline & \multicolumn{2}{|c|}{$\begin{array}{l}\text { Infant testing } \\
\text { (90 sec delay) }\end{array}$} & \multicolumn{2}{|c|}{$\begin{array}{l}\text { Juvenile testing } \\
\text { (90 sec delay) }\end{array}$} \\
\hline & $\begin{array}{l}\text { Percentage } \\
\text { correct }\end{array}$ & $\begin{array}{l}\text { Trials to } \\
\text { criterion }\end{array}$ & $\begin{array}{l}\text { Percentage } \\
\text { correct }\end{array}$ & $\begin{array}{l}\text { Trials to } \\
\text { criterion }\end{array}$ \\
\hline \multicolumn{5}{|l|}{ HVA } \\
\hline Medial prefrontal cortex & $0.45^{* *}$ & $-0.44^{* *}$ & $0.42^{*}$ & -0.37 \\
\hline Anterior cingulate cortex & $0.39^{*}$ & -0.35 & 0.20 & -0.33 \\
\hline Caudate nucleus & 0.21 & -0.04 & 0.21 & -0.13 \\
\hline Nucleus accumbens & 0.20 & -0.21 & 0.06 & -0.33 \\
\hline \multicolumn{5}{|l|}{ 5-HIAA } \\
\hline Medial prefrontal cortex & 0.01 & -0.16 & $0.41^{*}$ & $-0.41^{*}$ \\
\hline Anterior cingulate cortex & 0.09 & -0.13 & 0.09 & -0.11 \\
\hline Caudate nucleus & 0.26 & -0.31 & 0.01 & -0.05 \\
\hline Nucleus accumbens & 0.26 & -0.33 & 0.30 & -0.26 \\
\hline
\end{tabular}

There were no group differences in norepinephrine levels, and no significant correlation between level of norepinephrine and any performance measure.

$* p<0.05$.

** $p<0.01$

group 2, we think it likely that the Phe manipulation (rather than the genetic differences) was also responsible for the observed effects in group 1 . The results were comparable for males and females.

In the present study we found a significant deficit on the delayed alternation task, a well-established measure of the cognitive functions dependent on prefrontal cortex (e.g., Jacobsen and Nissen, 1937; Bättig et al., 1960; Gross, 1963; Kubota and Niki, 1971; Wikmark et al., 1973; Niki, 1971; Larsen and Divac, 1978; Bubser and Schmidt, 1990). Success when no delay is imposed, but failure with a delay (as we found in infant rats in groups 1 and 2, and in juvenile rats in group 1), is characteristic of the performance of primates with lesions of dorsolateral prefrontal cortex (e.g., Bättig et al., 1960), although these lesioned primates often fail at even short delays (such as 10 sec or less), which we did not find here. [dorsolateral prefrontal cortex in primates is generally considered to be the homolog of medial prefrontal cortex in rats (Leonard, 1969; Domesick, 1972; Kolb, 1984; Groenewegen, 1988)]. Lesions of medial prefrontal cortex in rats often produce deficits on delayed alternation even at the $0 \mathrm{sec}$ delay (e.g., Freeman and Stanton, 1992), presumably because it takes $1-2 \mathrm{sec}$ to move the rat from the goal arm to the start box even when no additional delay is imposed. This is the pattern of performance we found in juvenile rats in group 2 . Thus, our findings in animals with moderately elevated Phe levels are comparable to those previously reported in animals with lesions of prefrontal cortex. This deficit on a prefrontal cortex task produced by mild elevations in Phe is also consistent with the report by Diamond, Hurwitz, Lee, Grover, and Minarchik (unpublished observations) of deficits on nine of nine measures of the cognitive functions dependent on prefrontal cortex in children with mild, chronic elevations in plasma Phe due to mild hyperphenylalaninemia or treated PKU.

Neonatal lesions of medial prefrontal cortex in the rat severely impair delayed alternation performance in P19 and P23 infant rats, mildly impair performance in P27 infant rats, and no longer significantly affect delayed alternation performance by P33 (Freeman and Stanton, 1992; see also Kolb and Nonneman, 1978; Nonneman and Corwin, 1981; Vicedomini et al., 1982a,b, 1984). We found the severest deficits in group 1 when they were tested as infants. For example, their impairment at the $90 \mathrm{sec}$ delay at P26 was more severe than their impairment at the same delay at P46, consistent with the effects found after lesions of prefrontal cortex by Freeman and Stanton (1992). Group 2 showed some difficulty transferring what they had learned in the infant maze to the adult maze. Hence, their impaired performance in the adult maze on initial sessions at the 0 sec delay. Although the animals in group 2 showed some impairment at the $90 \mathrm{sec}$ delay, the impairment might have becn morc pronounced had they been tested closer to P20 on this delay, when lesions of prefrontal cortex have their most severe effects on performance of this task.

We found that dopamine metabolism was depressed in frontal cortex. In fact, the strongest neurochemical effect was on HVA levels in the two frontal cortical areas. It was not the only effect, however. For example, decreased HVA levels were also found in the nucleus accumbens, although no significant effect was found on HVA levels in the striatum. The different results for the accumbens and striatum are consistent with other findings (Acworth et al., 1988) and are to be expected given the higher rate of dopamine turnover in the accumbens (Bannon and Roth, 1983). The absence of any effect on norepinephrine is also consistent with previous work demonstrating that norepinephrine levels are relatively insensitive to alterations in precursor (Irie and Wurtman, 1987).

The levels of 5-HIAA were reduced in all brain regions examined. Some effect on 5-HIAA was to be expected given that 5-HT levels in the brain are sensitive to levels of the serotoninergic precursor (tryptophan; Fernstrom and Wurtman, 1971), and given that tryptophan, being a large neutral amino acid, must (like tyrosine) compete with Phe to cross the blood-brain barrier. The protein-carrier's affinity for tryptophan is roughly midway between that for Phe and tyrosine; the effect that we found on prefrontal 5-HIAA was roughly half that of the effect we found on prefrontal HVA. The plasma ratio of Phe:tryptophan should not be as imbalanced in those treated for PKU as the ratio of Phe:tyrosine. That is because the absolute level of tryptophan in blood should be unaffected, whereas the absolute level of tyrosine is often lowered due to the impairment in converting Phe to tyrosine. Because the absolute levels of tryp- 
tophan are not reduced and because tryptophan competes more successfully with Phe than does tyrosine in crossing the bloodbrain barrier, we think the main effect of mild Phe elevations in those with impairments in the Phe hydroxylating system should be on cerebral levels of the dopamine precursor, tyrosine. The additional effect on 5-HT metabolism in the present study may have occurred because plasma Phe levels were raised slightly more than intended, especially since high concentrations of Phe in the brain competitively inhibit tryptophan hydroxylase activity (in much the same way that these concentrations inhibit the activity of tyrosine hydroxylase; Levitt et al., 1965; Lovenberg et al., 1968; McKean, 1972).

The results of the present study contrast with previous studies that have failed to document effects of mild elevations of Phe. In such studies, generalized measures of performance, such as IQ tests, and global measures of metabolites (from cerebrospinal fluid) were used. On measures as global as IQ tests even patients in whom frontal cortex has been surgically removed score within the normal range (e.g., Stuss and Benson, 1986, 1987). Since there is much less HVA in frontal cortex than in the striatum and other brain regions, a change in HVA in frontal cortex alone would be unlikely to significantly affect the levels of IIVA in cerebrospinal fluid. Similarly, when previous work has failed to find an effect of acute, mild elevations of Phe in animals this has been because the investigators were looking in regions that are relatively unaffected (e.g., the striatum) or in whole brain tissue that could miss region-specific effects. For example, Arvin et al. (1992) found that increased Phe in plasma had no effect on extracellular dopamine levels in the striatum. The striatum was a logical brain region in which to investigate possible effects of Phe on dopamine because the striatum is the brain region with the highest levels of dopamine. However, striatal dopaminergic neurons appear to be protected against small perturbations in the level of precursor by their autoreceptors, their lower activity, and their slower rates of dopamine turnover.

Although frontal cortex has less dopamine than areas such as the striatum, this does not mean that dopamine is unimportant for frontal cortex function. On the contrary, depletion of dopamine or inhibition of dopamine receptors in prefrontal cortex produces behavioral impairments comparable to those produced by destruction or removal of prefrontal cortex (Brozoski et al., 1979; Simon et al., 1980; Stam et al., 1989; Sawaguchi and Goldman-Rakic, 1991). In one study with nonhuman primates, depletion of nearly $90 \%$ of the dopamine in prefrontal cortex was required to achieve this effect (Brozoski et al., 1979), but when this has been studied in the rat, the deficit in delayed alternation performance has been found with dopamine reductions more comparable to those reported here (32\% of controls, Simon et al., 1980; 29\% of controls, Stam et al., 1989).

It is unlikely that effects on the dopaminergic system outside of frontal cortex or effects on other neurotransmitter systems were responsible for the observed impairment in delayed alternation performance for the following reasons. (1) Only dopamine metabolism in prefrontal cortex was significantly related to every measure of performance on the delayed alternation task. Previous work has demonstrated similar correlations (Sahakian et al., 1985). Indeed, Sahakian and colleagues found no significant correlations between 5-HT levels in cortex or in subcortical areas and delayed alternation performance, whereas they found that the correlation between cortical dopamine levels and delayed alternation performance was significant. (2) Our con- clusion that the observed impairment in delayed alternation performance is due to effects on the dopaminergic system in frontal cortex is consistent with previous work demonstrating that while success on delayed alternation is highly dependent on the level of dopamine specifically in prefrontal cortex, it is not dependent on 5-HT or norepinephrine levels in the same region (Brozoski et al., 1979). Brozoski and colleagues found that depletions of norepinephrine or 5-HT in prefrontal cortex, comparable in magnitude to the depletions of prefrontal dopamine, had no effect on delayed alternation performance. (3) Our conclusion is also consistent with previous work demonstrating that success on delayed alternation is not dependent on dopamine levels elsewhere in the brain, such as in the striatum, hippocampus, or hypothalamus, or on norepinephrine or 5-HT concentrations in those regions (Simon ct al., 1980; Sahakian et al., 1985). (4) The lack of correlation we found between observed neurochemical changes in the nucleus accumbens and delayed alternation performance is consistent with evidence that ablation of the nucleus accumbens does not affect performance on a similar task (Annett et al., 1989).

There is some evidence linking the caudate nucleus, which receives a strong projection from prefrontal cortex, to delayed alternation performance (e.g., Bättig et al., 1960; Goldman and Rosvold, 1972; Vicedomini et al., 1982b). However, in the present study, HVA levels in the caudate were not significantly lowered and dopamine levels were only minimally affected (reduced less than half as much as those in prefrontal cortex). Therefore, it is unlikely that the observed impairment in delayed alternation performance was due to effects on the striatal dopaminergic system.

The levels of HVA and 5-HIAA in the anterior cingulate cortex were significantly reduced in the present study. The effect on HVA in the anterior cingulate is consistent with reports that the segregation between the dopamine neurons projecting to medial prefrontal cortex and anterior cingulate cortex is less complete than once thought (e.g., Loughlin and Fallon, 1984). The role of the anterior cingulate in performance of delayed alternation or similar tasks, such as delayed response, has received little attention. This region, like medial prefrontal cortex, is an association area in frontal cortex. Given recent evidence demonstrating the importance of the anterior cingulate for cognitive performance in humans (Pardo et al., 1990, 1991; Corbetta et al., 1991; Grossman et al., 1992; Paus et al., 1993), it is not as unlikely as it once seemed that this region might be important for delayed alternation performance as well. This may deserve further study. There is evidence, however, that partial damage to anterior cingulate cortex has no effect on performance of delayed alternation (Larsen and Divac, 1978; Thomas and Brito, 1980).

The role of 5-HT and the interrelations between 5-HT and dopamine in the functions of prefrontal cortex have not received a great deal of attention; it too might merit closer examination. (In the present study, 5-HIAA levels in prefrontal cortex also showed somc rclation to delayed alternation performance.) $\mathrm{Fu}$ ture work is also needed to confirm the present findings using tasks that do not require prefrontal cortex in addition to tasks that do, to look at other areas of the brain, to measure tyrosine as well as Phe, and to measure DOPAC and 5-HT levels as well as the neurochemical variables assessed here. Future work should be done to confirm that the prefrontal dopaminergic system is selectively affected by Phe levels in the range of $6-10 \mathrm{mg} / \mathrm{dl}$, and that the effect on dopamine metabolism is due to elevations 
in Phe and not to the $\alpha$-methylphenylalanine that was administered here along with Phe.

In summary, the results of the present study accord well with the mechanism we hypothesized to account for the children's cognitive deficits. We had predicted that moderate elevations in Phe would depress dopamine metabolism in prefrontal cortex, impairing the cognitive functions prefrontal cortex subserves. We had predicted this would occur because moderate increases in Phe relative to tyrosine in plasma moderately reduce the amount of tyrosine crossing the blood-brain barrier. Most dopaminergic systems in the brain are insensitive to modest changes in available tyrosine, but not the prefrontal dopaminergic system, whose neurons have higher levels of activity and of dopamine turnover. In our model of mild, chronic elevations in plasma Phe early in life, performance on a task dcpendent on frontal cortex was impaired and dopamine metabolism in frontal cortex (medial prefrontal cortex and anterior cingulate cortex) was reduced. For children whose Phe levels remain moderately elevated despite strict adherence to a low-Phe diet, these results provide reason for hope-the problem appears to be primarily in the frontal dopaminergic system and should be amenable to a drug treatment targeted to that system. Additional evidence of the specificity of the effects comes from Diamond, Hurwitz, Lee, Grover, and Minarchik (unpublished observations): children with mild plasma Phe elevations were impaired on all tests of frontal cortex function but were unimpaired on control tasks that required the functions of parietal cortex or the medial temporal lobe. In any future treatment that includes tyrosine supplementation, it will be important to monitor whether this exacerbates the changes observed here in the serotoninergic system, since tryptophan would then have to compete with elevated levels of both tyrosine and Phe. For those concerned with the possible deleterious effects of food additives high in Phe (such as Nutrasweet or Equal), the present results indicate where to look to see if there is indeed cause for concern.

\section{References}

Acworth IN, During MJ, Wurtman RJ (1988) Processes that couple amino acid availability to neurotransmitter synthesis and release. In: NATO ASI series, H20, Amino acid availability and brain function in health and disease (Huether G, ed), pp 117-136. Berlin: Springer.

Annett LE, McGregor A, Robbins TW (1988) The effects of ibotenic acid lesions of the nucleus accumbens on spatial learning and extinction in the rat. Behav Brain Res 31:231-242.

Arvin B, Chapman AG, Meldrum BS (1992) Extracellular levels of monoamines in striatum of baboon and rat following oral phenylalanine. Soc Neurosci Abstr 18:24.

Bannon MJ, Roth RH (1983) Pharmacology of mesocortical dopamine neurons. Pharmacol Rev 35:53-68.

Bannon MJ, Bunney EB, Roth RH (1981a) Mesocortical dopamine neurons: rapid transmitter turnover compared to other brain catecholamine systems. Brain Res 218:376-382.

Bannon MJ, Michaud RL, Roth RH (1981b) Mesocortical dopamine neurons. Lack of autoreceptors modulating dopamine synthesis. Mol Pharmacol 19:270-275.

Bannon MJ, Reinhard JF Jr, Bunney EB, Roth RI (1982) Unique response to antipsychotic drugs is due to absence of terminal autoreceptors in mesocortical dopamine neurons. Nature 296:444-446.

Bättig K, Rosvold HE, Mishkin M (1960) Comparison of the effects of frontal and caudate lesions on delayed response and alternation in monkeys. J Comp Physiol 53:400-404.

Berger B, Tassin JP, Blanc G, Moyne MA, Thierry AM (1974) Histochemical confirmation for dopaminergic innervation of the rat cerebral cortex after destruction of the noradrenergic ascending pathways. Brain Res 81:332-337.

Berger B, Thierry AM, Tassin JP, Moyne MA (1976) Dopaminergic innervation of the rat prefrontal cortex: a fluorescence histochemical study. Brain Res 106:133-145.

Berger B, Verney C, Alvarez C, Vigny A, Helle KB (1985) Postnatal ontogenesis of the dopaminergic innervation in the rat anterior cingulate cortex (area 24). Immunocytochemical and catecholamine fluorescence histochemical analysis. Dev Brain Res 21:31-47.

Bcrry HK, O'Grady DJ, Perlmutter LJ, Bofinger MK (1979) Intellectual development and academic achievement of children treated early for phenylketonuria. Dev Med Child Neurol 21:311-320.

Bessman SP, Acosta P, Harper R, Towell M (1988) Essential nature of the "dispensable" amino acids and their possible influence on the development and function of the brain. In: NATO ASI series, H20, Amino acid availability and brain function in health and disease (Huether G, ed), pp 13-19 [see especially p 15]. Berlin: Springer.

Bickel H, Gerrard J, Hickmans EM (1954) The influence of phenylalanine intake on the chemistry and behavior of a phenylketonuric child. Acta Pediatr 43:64-77.

Bradberry CW, Karasic DH, Deutch AY, Roth RH (1989) Regionallyspecific alterations in mesotelencephalic dopamine synthesis in diabetic rats: association with precursor tyrosine. J Neural Transm 78: 221-229.

Brass CA, Greengard O (1982) Modulation of cerebral catecholamine concentrations during hyperphenylalaninaemia. Biochem J 208:765771.

Brass CA, Issacs CE, McChesney R, Greengard O (1982) The effects of hyperphenylalaninemia on fetal development: a new animal model of maternal phenylketonuria. Pediatr Res 16:388-394.

Brodmann K (1909) Vergleichende Lokalisations-lehre der Grosshirnrinde in inron prinzipien dargestellt auf Grund des Zellenbaues. Leipzig: Barth.

Brozoski TJ, Brown RM, Rosvold HE, Goldman PS (1979) Cognitive deficit caused by regional depletion of dopamine in prefrontal cortex of rhesus monkey. Science 205:929-932.

Bubser M, Schmidt WJ (1990) 6-Hydroxydopamine lesion of the rat prefrontal cortex increases locomotor activity, impairs acquisition of delayed alternation tasks, but does not affect uninterrupted tasks in the radial maze. Behav Brain Res 37:157-168.

Cabalska B, Duczyňska N, Borzymowska J, Zorska K, Košlacz-Folga A, Božkowa K (1977) Termination of dietary treatment for phenylketonuria. Eur J Pediatr 126:253-262.

Chiodo LA, Bannon MJ, Grace AA, Roth RH, Bunney BS (1984) Evidence for the absence of impulse-regulating somatodendritic and synthesis-modulating nerve terminal auto-receptors on subpopulations of mesocortical dopamine neurons. Neuroscience 12:1-16.

Chirigos M, Greengard P, Undenfriend S (1960) Uptake of tyrosine by rat brain in vivo. J Biol Chem 235:2075-2079.

Corbetta M, Miezin FM, Dobmeyer S, Shulman GL, Petersen SE (1991) Selective and divided attention during visual discriminations of shape, color, and specd: functional anatomy by positron emission tomography. J Neurosci 11:2383-2402.

Cowie VA (1971) Neurological and psychiatric aspects of phenylketonuria. In: Phenylketonuria and some other inborn errors of amino acid metabolism (Bickel H, Hudson F, Woolf L, eds), pp 29-39. Stuttgart: Theime.

DelValle JA, Dienel D, Greengard O (1978) Comparison of $\alpha$-methylphenylalanine and $p$-chlorophenylalanine as inducers of chronic hyperphenylalaninaemia in developing rats. Biochem J 170:449-459.

Deutch AY, Tam S-Y, Roth RH (1985) Footshock and conditioned stress increase 3,4-dihydroxyphenylacetic acid (DOPAC) in the ventral tegmental area but not substantia nigra. Brain Res 333:143-146.

DiLella AG, Marvit J, Lidsky AS, Güttler F, Woo SLC (1986) Tight linkage between a splicing mutation and a specific DNA haplotype in phenylketonuria. Nature 322:799-803.

Domesick VB (1972) Thalamic relationships of the medial cortex in the rat. Brain Behav Evol 6:457-483.

Fernstrom JD, Wurtman RJ (1971) Brain serotonin content: physiological dependence on plasma tryptophan levels. Science 173:149151 .

Freeman JH, Stanton ME (1991) Fimbria-fornix transections disrupt the ontogeny of delayed alternation but not position discrimination in the rat. Behav Neurosci 105:386-395.

Freeman JH, Stanton ME (1992) Medial prefrontal cortex lesions and spatial delayed alternation in the developing rat: recovery or sparing. Behav Neurosci 106:924-932.

Fuxe K (1965) Evidence for the existence of monoamine neurons in the central nervous system. VI. Distribution of monoamine nerve 
terminals in the central nervous system. Acta Physiol Scand [Suppl] 247:39-85.

Goldman PS, Rosvold HE (1972) The effects of selective caudate lesions in infant and juvenile rhesus monkeys. Brain Res 43:53-56.

Green RJ, Stanton ME (1989) Differential ontogeny of working memory and reference memory in the rat. Behav Neurosci 103:98-105.

Greengard O, Yoss MS, DelValle JA (1976) $\alpha$-Methylphenylalanine, a new inducer of chronic hyperphenylalaninemia in suckling rats. Science 192:1007-1008.

Groenewegen HJ (1988) Organization of the afferent connections of the mediodorsal thalamic nucleus in the rat, related to the mediodorsal-prefrontal topography. Brain Res 24:379-431.

Gross CG (1963) Effect of deprivation on delayed response and delayed alternation performance by normal and brain operated monkeys. J Comp Physiol Psychol 56:232-236.

Grossman M, Crino P, Reivich M, Stern MB, Hurtig HI (1992) Attention and sentence processing deficits in Parkinson's disease: the role of anterior cingulate cortex. Cereb Cortex 2:513-525.

Guthrie RE, Susi A (1963) A simple phenylalanine method for detecting phenylketonuria in large populations of newborn infants. Pediatrics 32:338-343.

Güttler F, Ledley FD, Lidsky AS, DiLella AG, Sullivan SE, Woo SLC (1987) Correlation between polymorphic DNA haplotypes at the phenylalanine hydroxylase locus and clinical phenotypes of phenylketonuria. J Pediatr 110:68-71

Hsia DY-Y (1970) Phenylketonuria and its variants. Prog Med Genet 7:29-68.

Hudson FP, Mordaunt VL, Leahy I (1970) Evaluation of treatment begun in first three months of life in 184 cases of phenylketonuria. Arch Dis Child 45:5-12.

Ikeda M, Levitt M, Udenfriend S (1967) Phenylalanine as substrate and inhibitor of tyrosine hydroxylase. Arch Biochem Biophys 120: $420-427$.

Irie K, Wurtman RJ (1987) Release of norepinephrine from rat hypothalamic slices: effects of desipramine and tyrosine. Brain Res 432: 391-394.

Jacobsen CF, Nissen HW (1937) Studies of cerebral function in primates. The effects of frontal lobe lesions on the delayed alternation habit in monkeys. J Comp Physiol Psychol 23:101-112.

Kalsbeek A, Voorn P, Buijs RM, Pool CW, Uylings HBM (1988) Development of the dopaminergic innervation in the prefrontal cortex of the rat. J Comp Neurol 269:58-72.

Kerr GR, Chamove AS, Harlow HS, Waisman HA (1968) Fetal PKU: The effect of maternal hyperphenylalaninemia during pregnancy in the rhesus monkey. Pediatrics 42:27-36.

Kolb B (1984) Functions of the frontal cortex of the rat: a comparative review. Brain Res Rev 8:65 98.

Kolb B, Nonneman AJ (1978) Sparing of function in rats with early prefrontal cortex lesions. Brain Res 151:135-148.

Krause WL, Helminski M, McDonald L, Dembure P, Salvo R, Freides D, Elsas LJ (1985) Biochemical and neuropsychological effects of elevated plasma phenylalanine in patients with treated phenylketonuria, a model for the study of phenylalanine in brain function in man. J Clin Invest 75:40-48.

Kubota K, Niki H (1971) Prefrontal cortical unit activity and delayed alternation performance in monkeys. J Neurophysiol 34:337-347.

Larsen JK, Divac I (1978) Selective ablations within the prefrontal cortex of the rat and performance on delayed alternation. Physiol Psychol 6:15-17.

Ledly FD, Levy HL, Woo SL (1986) Molecular analysis of the inheritance of phenylketonuria and mild hpherphenylalaninemia in families with both disorders. N Engl J Med 314:1276-1280.

Lenke RR, Levy H (1980) Maternal phenylketonuria and hyperphenylalaninemia. An international survey of the outcome of untreated and treated pregnancies. N Engl J Med 303:1202.

Leonard CM (1969) The prefrontal cortex of the rat. I. Cortical projections of the mediodorsal nucleus. II. Efferent connections. Brain Res 12:321-343.

Levitt M, Spector S, Sjoerdsma A, Udenfriend S (1965) Elucidation of the rate-limiting step in norepinephrine biosynthesis in the perfused guinea-pig heart. J Pharmacol Exp Ther 148:1-8.

Levy HL, Waisbren SE (1983) Effects of untreated maternal phenylketonuria and hyperphenylalaninemia on the fetus. N Engl J Med 309:1269-1274.

Levy HL, Shih VE, Karolkewicz V, French WA, Carr JR, Cass V,
Kennedy JL, MacCready RA (1971) Persistent mild hyperphenylalaninemia in the untreated state. N Engl J Med 285:424-428.

Lidsky AS, Law ML, Morse HG, Kao FT, Woo SLC (1985) Regional mapping of the human phenylalanine hydroxylase gene and the PKU locus on chromosome 12. Proc Natl Acad Sci USA 82:6221-6225.

Lindvall O, Bjorklund A (1978) Organization of catecholamine neurons in the rat central nervous system. In: Handbook of psychopharmacology, Vol 9 (Iversen LL, Iversen SD, Snyder SH, eds), pp 139-231. New York: Plenum.

Lindvall O, Bjorklund A, Divac I (1978) Organization of catecholamine neurons projecting to the frontal cortex in the rat. Brain Res 142:1-24.

Loughlin SE, Fallon JH (1984) Substantia nigra and ventral tegmental area projections to cortex: topography and collateralization. Neuroscience 11:425-435.

Lovenberg W, Jequier E, Sjoerdsma A (1968) Tryptophan hydroxylation in mammalian systems. In: Advances in pharmacology $6 \mathrm{~A}$ (Garratini S, Shore PA, eds), pp 21-36. New York: Academic.

McDonald JD, Bode VC, Dove WF, Shedlovsky A (1990) Pahhph-5: a mouse mutant deficient in phenylalanine hydroxylase. Proc Natl Acad Sci USA 87:1965-1967.

McKean CM (1972) The effects of high phenylalanine concentrations on serotonin and catecholamine metabolism in the human brain. Brain Res 47:469-476.

Miller L, Braun LD, Pardridge WM, Oldendorf WH (1985) Kinetic constants for blood-barrier amino acid transport in conscious rats. J Neurochem 45:1427-1432.

Niki H (1974) Prefrontal unit activity during delayed alternation in the monkey. Brain Res 68:185-204.

Nonneman AJ, Corwin JV (1981) Differential effects of prefrontal cortex ablation in neonatal, juvenile, and young adult rats. J Comp Physiol Psychol 95:588-602.

Pardo JV, Pardo VJ, Janer KW, Raichle ME (1990) The arterior cingulate cortex mediates processing selection in the Stroop attentional conflict paradigm. Proc Natl Acad Sci USA 87:256-259.

Pardo JV, Fox PT, Raichle ME (1991) Localization of a human system for sustained attention by positron emission tomography. Nature 349 : 61-64.

Pardridge WM, Oldendorf WH (1977) Transport of metabolic substrates through the blood-brain barrier. J Neurochem 28:5-12.

Paus T, Petrides M, Evans AC, Meyer E (1993) Role of the human anterior cingulate cortex in the control of oculomotor, manual, and speech responses: a positron emission tomography study. $J$ Neurophysiol 70:453-469.

Reinhard JF, Bannon MJ Jr, Roth RH (1982) Acceleration by stress of dopamine synthesis and metabolism in prefrontal cortex: antagonism by diazepam. Naunyn Schmiedebergs Arch Pharmacol 318: 374-377.

Robinson MB, Heyes MP, Anegawa NJ, Gorry E, Djali S, Mellits ED, Batshaw ML (1992) Quinolinate in brain and cerebrospinal fluid in rat models of congenital hyperammonemia. Pediatr Res 32:483-488.

Roth RH (1984) CNS dopamine autoreceptors: distribution, pharmacology, and function. Ann NY Acad Sci 430:27-53.

Sahakian BJ, Sarna GS, Kantamaneni BD, Jackson A, Ilutson PH, Curzon $G$ (1985) Association between learning and cortical catecholamines in non-drug-treated rats. Psychopharmacology 86:339 343.

Sawaguchi T, Goldman-Rakic PS (1991) D1 dopamine receptors in prefrontal cortex: involvement in working memory. Science 251:947950.

Simon H, Scatton B, LeMoal M (1980) Dopaminergic A10 neurones are involved in cognitive functions. Nature 286:150-151.

Stam CJ, de Bruin JP, van Haelst AM, van der Gugten J, Kalsbeek A (1989) Influence of the mesocortical dopaminergic system on activity, food hoarding, social-agonistic behavior, and spatial delayed alternation in male rats. Behav Neurosci 103:24-35.

Stuss DT, Benson DF (1986) The frontal lobes. New York: Raven.

Stuss DT, Benson DF (1987) The frontal lobes and control of cognition and memory. In: The frontal lobes revisited (Perecman E, ed), pp 141-158. New York: IRBN.

Tam S-Y, Elsworth JD, Bradberry CW, Roth RH (1991) Mesocortical dopamine neurons: high basal firing frequency predicts tyrosine dependence of dopamine synthesis. J Neural Transm 81:97-110.

Thierry AM, Blanc G, Sobel A, Stinus L, Glowinski J (1973) Dopaminergic terminals in the rat cortex. Science 182:499-501. 
Thierry AM, Tassin JP, Blanc G, Glowinski J (1976) Selective activation of the mesocortical DA system by stress. Nature 263:242-243.

Thierry AM, Tassin JP, Blanc A, Stinus L, Scatton B, Glowinski J (1977) Discovery of the mesocortical dopaminergic system: some pharmacological and functional characteristics. Adv Biomed Psychopharmacol 16:5-12.

Thomas GJ, Brito GNO (1980) Recovery of delayed alternation in rats after lesions in medial frontal cortex and septum. J Comp Physiol Psychol 94:808-818.

Vicedomini JP, Corwin JV, Nonneman AJ (1982a) Role of residual anterior neocortex in recovery from neonatal prefrontal lesions in the rat. Physiol Behav 28:787-807.

Vicedomini JP, Corwin JV, Nonneman AJ (1982b) Behavioral effects of lesions to the caudate nucleus or mediodorsal thalamus in neonatal, juvenile, and adult rats. Physiol Psychol 10:246-250.

Vicedomini JP, Isaac WL, Nonneman AJ (1984) Role of the caudate nucleus in recovery from neonatal mediofrontal cortex lesions in the rat. Dev Psychol 17:51-65.

Vogt BA, Peters A (1981) Form and distribution of neurons in rat cingulate cortex: areas 32, 24 and 29. J Comp Neurol 195:603-625.
Wapnir RA, Dierks-Vertling C (1971) Placental transfer of amino acids in human in the rat. II. Aromatic amino acids. Biol Neonate 17:1373.

Welsh MC, Pennington BF, Ozonoff S, Rouse B, McCabe ERB (1990) Neuropsychology of early-treated phenylketonuria: specific executive function deficits. Child Dev 61:1697-1713.

Wikmark RGE, Divac I, Weiss R (1973) Delayed alternation in rats with lesions in the frontal lobes: implications for a comparative neuropsychology of the frontal system. Brain Behav Evol 8:329-339.

Williamson ML, Koch R, Azen C, Chang C (1981) Correlations of intelligence test results in treated phenylketonuric children. Pediatrics 68:161-167.

Woo SLC, Lidsky AS, Güttler F, Chandra T, Robson KJH (1983) Cloned human phenylalanine hydroxylase gene allows prenatal diagnusis and canier delection of classical phenylketonuria. Nature 306 151-155.

Zhang JS, Stellar E, Epstein A (1984) Together intracranial angiotensin and systemic mineralocorticoid produce avidity for salt in the rat. Physiol Behav 32:677-681. 